\title{
An Introduction to Classical Grounded Theory
}

\author{
Henny Suzana Mediani* \\ Associate Professor of Pediatric Nursing, Faculty of Nursing Universitas Padjadjaran Indonesia
}

Received: October 12, 2017; Accepted: October 23, 2017; Published: November 06, 2017

*Corresponding author: Dr. Henny Suzana Mediani, PhD, Associate Professor in Pediatric Nursing Faculty of Nursing, Universitas Padjadjaran Indonesia, Jl Raya Bandung Sumedang Km 21, Jatinangor, Sumedang Indonesia ; Tel: +62 227795596; Mobile: +6282217391965;Email: henny.mediani@unpad.ac.id

\begin{abstract}
The grounded theory approach has been used in nursing research since 1970. Despite the extensive use of grounded theory over the past 40 years and the publication of papers and methodological textbooks, many novice researchers faced difficulties in applying grounded theory approach in their studies. The purpose of this paper is to discuss what is grounded theory, how it came about, and how it is used that may be useful for novice researchers and graduate nursing students as they interested in using Classical or Glaserian grounded theory methods for the first time.
\end{abstract}

Keywords : Grounded theory; inductive research; method of nursing research; qualitative method

\section{Introduction}

Glasser and Strauss in 1967 published "The Discovery of Grounded Theory: Strategies for Qualitative Research" and this introduced the methodology of grounded theory (GT) [1]. Since then, grounded theory has become a "global" phenomenon. Recent years GT has seen there has been growing popularity and a rise in the use of GT method as an approach in qualitative research, and is often used in disciplines such as psychology, education, nursing and anthropology, health science, business and management $[2,3]$. Moreover, previous studies have been conducted in many countries, including such as the United States of America, United Kingdom, Canada, Australia, France, Sweden and Finland. Furthermore, not only are there thousands of publications that report on studies applying grounded theory methods, but there is also collection of seminal text that researchers can use to guide their study and ensure the rigour of their work [4]. This can be seen as evidence to the success of grounded theory [5]. Grounded theory has been an important methodology for nursing research [6]. However, literature has been identified and criticised for its lack of adherence to the method as explicated by its originators [7]. In this paper, the author describes grounded theory, how it came about, and how it is used that may be useful for novice researchers and graduate nursing students as they interested in using grounded theory methods. Literatures that explained and described GT method were reviewed.

\section{What is grounded theory?}

Glaser defines Grounded theory as a general inductive research method for the systematic generation new theory from data acquired by a rigorous research method and to present the processes going on in the field of study [8,9]. As a general methodology, grounded theory can use either qualitative or quantitative data or a combination of these $[2,8,10,11]$. But it has mainly been used with qualitative data and known as a qualitative methodology [6, 12,13]. Glaser seems to avoid labeling grounded theory as a qualitative methodology. Furthermore, rather than attributing grounded theory to symbolic interactionism, as do other grounded theories [8,9]. According to Glaser suggested that symbolic interactionism as one of sensitizing agents for developing concepts $[2,8]$. However, since Strauss was influenced by the Chicago School and Glaser notes that nursing research has mainly been used with qualitative research data and it is for this use that it is best known [6, 8,].

Grounded theory was developed for the purpose to create a new theory that is generated accounts for a pattern of behaviour that is relevant and also problematic for those involved who have an understanding of the phenomenon, rather than testing existing theory $[2,8,9,11,11,15]$.Grounded theory is based on assumptions that both knowledge and people are dynamic and that context facilities, hinder, or otherwise affects human goals and social psychological process [16]. The method is termed 'grounded' because the theory is systematically obtained from a broad array of data through a rigorous process of constant comparison and no time does researcher attempt to impose a theory from another study onto the data $[1,2,9,17]$. Put simply, grounded theory is a method to develop theory from data. This means that data from participants determine: (1) what is explored in the study; (2) the literature searched; (3) the research question developed; and (4) the number of participants in the study $[17,18]$.Grounded theory, in contrast to theory obtained by logic-deductive methods, is theory grounded in data which have been systematically obtained and analyzed through "social" research [19].It means that they worked out a way of developing theory empirically "from the bottom up "as a challenge to the more conventional way of developing it rationally, "from the top down". 
According to Glaser more than a framework for inquiry, grounded theory refers to a specific methodology that moves from the systematic of data collection to the development of multivariate conceptual theory [10]. Glaser suggests grounded theory as a complete methodological package which providing systematic methods for collecting data and creating theoretically complete, publishable theory, rich in imageric concepts and perceptual power [10].

The generation of a new theory using this method is an evolutionary process that occurs as the research is being conducted [6]. This research method does not start out from the circumstance of predefined concepts or an existing theory; the concept and properties emerge as the researcher gather, codes and analyses data $[1,15,20,21,22]$.

Grounded theory is a research approach that results in the development of middle-range theory at a substantive or formal level $[2,9]$. This explicit goal of theory generation makes grounded theory unique and different from other qualitative research methods $[1,2,23,24]$. In their original text, Glaser and Strauss differentiated 'substantive theory' from formal theory [1]. Substantive theory is developed from research conducted in one specific area or contextual situation, such as patient care. Formal theory development is more conceptual. An example of the substantive theory approach would be research into pain or violence [1].

\section{Why is Grounded Theory an important method?}

Because the GT method captures social process in social context, this research approach is most useful when the goal is a framework or theory that explains human behaviour in context $[1,9]$. Grounded Theory offers a useful approach for nursing researchers who wish to investigate social-psychological processes and generate theoretical explanations for them [14].

Grounded theorists support the view that each member experiences a basic social psychological problem not usually made explicit or articulated by the group [7]. Grounded Theory is known as an effective way of discovering the participants' primary concern, the core category or core concern/problem; and how the participants handle their life circumstances, the core process [1, $6,25,26,27]$. Thus, GT provides tools to discover the participants' core problem and to generate a theoretical conceptualization derived from living phenomena. By developing theory, researchers seek to understand the problem situation as experienced by a group of participants and how they deal with this problem $[2,8]$. It is problem-focused because this approach involves investigating how people experiences and resolve their everyday problems $[2,5,8]$. Thus the theory emerged through this method is focused on explaining how those problem are resolved [8].Thus, in a GT study, participants provide data that reflect their concerns. It is important that the researcher understand, and ask questions about, what is happening. In GT the researcher must continually ask, 'What is going on?' and, 'What is the main problem of the participants and how are they trying to solve it?' $[2,8,9]$. These questions will be answered by discovering the core category and its sub-categories, and the properties of the data. A core category is the highest-level concept of the theory, relating to other categories and properties of the grounded theory; however it does not indicate how the different categories are related to each other $[2$, $8,9]$.

Classical GT or Glaserian Grounded Theory (GGT) is better equipped than other forms of GT to produce a clear, accurate understanding of what is actually happening in the data and what is really going on $[8,9,28]$. Grounded Theory does not aim for 'truth' but to conceptualize what is going on by using empirical data $[1,2,9]$. Thus the researcher must be immersed in the data in order to understand the events described and proceed from data collection to analysis, and on to organizing concepts and relationships into a theory [2]. The theory gathered by this approach can be clarified and refined by asking questions which can provide more in-depth knowledge about categories. Implicit in this process is the practice of constantly comparing data [14].

\section{How does grounded theory approach work?}

Glaser suggests that it is important to understand grounded theory as a package of research methods, which includes"... data collection, coding and analyzing through memoing, theoretical sampling and sorting to writing, utilizing the constant comparative method" [8]. It means that the sampling methods, data collection and data analysis cannot be considered as separate procedural steps in research process but instead should be considered as a continuous process of sampling, data collection and analysis. Glaser suggested that grounded theory refers to a specific methodology provides systematic methods for collecting data and establishing theoretical complete, publishable theory, rich in imageric concepts and perceptual power [10]. In GT method theoretical sampling and constant comparative method are specific unique method [2,9]. Theoretical sampling regards the process data collection, where new targets for participant are directed by the result collected from the preceding sample, when the theory emerges and the investigation become focuses, so too does purposive sampling or selective sampling. Constant comparative method is the simultaneous and concurrent process of coding and analyzing the collected data $[1,2,8,9]$. Therefore, the grounded theory, along with its constant comparison technique, allows a researcher to identify patterns and relationships between these patterns [2, 9].

Grounded theory approach is as a research process $[2,8,9]$. The research theory approach is difference with the traditional research approach (Figure 1). According to the traditional research approach, a research process is replicated by identifying the phenomena and by naming the research problems. Then after the data have been collected and analyzed, the results and conclusions are reported. Meanwhile, when the grounded theory approach is applied, however, the research process does not need 
to follow chronological stages of the traditional research process [20]. In grounded theory study, data collection, coding and analysis is occurring at the same time $[1,2,9]$. The process is not impeded by the development of research problems, theoretical understanding, or literature review. Instead the researcher is granted the freedom to enter the field and discover the main concern of participants and to identify participant approaches to resolving the problems experienced $[8,9]$. Grounded theory is founded on the conceptualization of data through coding, using constant comparative method. Through analysis, data-mainly in the form of transcripts, field-note observations, written data or literature-are sorted into conceptual codes. Then, during a process of comparison, these individual codes are compared, and arranged to form meaningful categories. Finally, through a process of abstraction, these categories build, and are refined until they are able to lead the researcher toward the development of substantive theory or conceptual hypotheses $[1,2.9,15]$

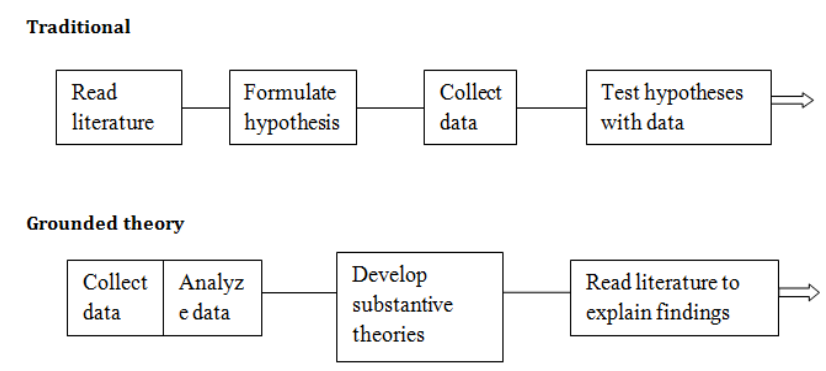

Figure 1:Comparison of traditional research methods to Grounded theory [29]

Throughout the analysis process, memos are written to capture emerging ideas about concepts and their relationships [8, 9]. This process of collecting data to develop the hypotheses and further identify properties and relationships among concepts is called theoretical sampling $[1,9]$. The emerging theory is further integrated by theoretical coding, a process of examining the data in theoretical rather than descriptive terms [9]. Diagramming relationships among concepts increases the level of abstraction. As data collection and analysis proceed, a core category that explains the main concern for the participants is identified [8,9]. A core category becomes the central phenomenon around which all other categories are integrated into a conceptual framework $[1,9,23]$. A core category can be theoretically modeled as a basic social process that accounts for most of the variation over time, in context and in behaviour, in the studied area [2,9]. When the core category is identified, researchers conduct a literature review to learn what has been published about the emerging concepts [17]; the literature is theoretically sampled for what it can contribute to the developing theory [24]. An important characteristic of grounded theory is modifiability as new data are generated [2, $9,24]$.

\section{When is Grounded Theory an appropriate ap- proach?}

Because the GT method captures social process in social context, this research approach is most useful when the goal is a framework or theory that explains human behaviour in context $[1,9]$. Grounded Theory offers a useful approach for nursing researchers who wish to investigate social-psychological processes and generate theoretical explanations for them [14]. Grounded theorists support the view that each member experiences a basic social psychological problem not usually made explicit or articulated by the group [7]. Grounded Theory is known as an effective way of discovering the participants' primary concern, the core category or core concern/problem; and how the participants handle their life circumstances, the core process $[1,6$, $26,27]$. Thus, GT provides tools to discover the participants' core problem and to generate a theoretical conceptualization derived from living phenomena. By developing theory, researchers seek to understand the problem situation as experienced by a group of participants and how they deal with this problem $[2,8]$.

\section{Grounded theory and nursing research}

Grounded theory has been embraced by nurses since the early 1970s [6, 15, 30,31]. Grounded theory is useful for directing nursing practice because it is an explanatory theory of human behaviour within a social context [24, 30]. A grounded theory approach provides nursing with a feasible means of generating theory about dominant psychosocial processes that present within human interactions, theory that is grounded in the realities of everyday clinical practice [6]. Grounded theory has been used to study a wide range of issues in practice settings such as pain management in children's wards in Indonesia [32]. the quality of nursing care in acute-care hospitals managing depression among black West Indian Canadian women examining the way parents access health care for their children and restructuring life for fire victims [33-37]. Grounded theory is applicable to a wide variety of issues relevant to clinical practice and can make an important contribution to the development of a theoretical base for clinical nursing and midwifery practice [31].

\section{Conclusion}

Grounded theory is well suited to nursing inquiry because it explains what is actually occurring in a situation at a certain time, rather than simply describing what is predicted to occur. It is the method of choice when knowledge about how people organize their lives within the framework of nursing in the contemporary health care system is sought. Moreover, grounded theory is recognized as a desirable research method when examining the field of nursing, because it produces a substantive or formal theory. As such, this method facilitates the generation of rich, complex and dense theory and can be used to generate new theory and understanding about a phenomenon, rather than test existing theory. Grounded theory as a methodology has the potential to provide 
insight into a complex phenomenon, such as nurses' pain management practice when caring for hospitalized children. From a nursing perspective, grounded theory provides a method to facilitate researchers who need to engage the clinical situation in an attempt to discover and construct a meaningful account of the phenomenon being studied. Thus, the grounded theory methodology is valuable to nursing studies as its objective of a developing a substantive theory grounded in the realities of everyday clinical situations provides a way to inform both nursing practice and research. This paper will enhance beginning researchers' awareness of the scientific rigour required of grounded theory research.

The methodology is based on a systematic set of data collection and constant comparative analysis among or between groups of participants in the area of research interest [1, 2, 9]. Grounded theory is a combination of both inductive and deductive approach. In order to identify the emerging substantive theory and gain an understanding of the phenomena under scrutiny, the primary approach taken in grounded theory is inductive, as the researcher is continually guided by the data and its subsequent patterns, codes and categories [1, 2, 6, 9].Grounded theory researchers do not formulate their hypotheses in advance since preformed hypotheses are prohibited $[1,20]$.Thus the researcher investigates and tries to get an in-depth understanding of a particular phenomenon by examining the similarities and differences that exist in the data collected in the field. The researcher analyses the data and tries to look for links that exist within the data, and hypothesizes about the data's relationship with the phenomenon, to generate a draft theory. The researcher aims also to discover the participants' main concern and how they continually try to solve it [29]. However, there is also a deductive element to the method. Once initial data have been collected and analyzed, the researcher follows a process of theoretical sampling, using the initial analysis to deduce where to go next to further data collection and enhance the developing theory $[2,8,9]$.

\section{Acknowledgement \\ Declaration of Conflicting Interests}

The Author(s) declared no potential conflicts of interest with respect to the research, authorship, and/or publication of this article.

\section{Funding}

The author(s) disclosed of the following financial support for the research, authorship, and/ or publication of this article. As part of the main researcher PhD study was funded by Directorate Research Higher Degree Ministry of Education Indonesia and Curtin University of Australia.

\section{References}

1. Glaser BG, Strauss AL. The discovery of grounded theory: strategies for qualitative research. Transaction Publishers. 1967.

2. Glaser BG. Emergence vs. forcing: basis of grounded theory analysis. Sociology Press. 1992.

3. Glaser BG, Holton J. Remodelling grounded theory. Forum: Qualitative Social Research. 2004:5(2).

4. Eaves YD. A synthesis technique for grounded theory data analysis. J Adv Nurs. 2001;35(5):654-663.

5. Gibson B, Hartman J. Rediscovering Grounded Theory. 2013.

6. Speziale H, Carpenter D. Qualitative research in nursing: advancing the humanistic imperative. Lippincott Williams \& Wilkins. 2007.

7. Wilson HS, Hutchinson SA. Methodologic mistakes in grounded theory. Nurs Res. 1996;45(2):122-124.

8. Glaser BG. Doing Grounded Theory: issues and discussions. Sociology Press. 1998.

9. Glaser BG. Theoretical sensitivity: advances in the methodology of grounded theory. Sociology Press. 1978.

10. Glaser BG. The future of grounded theory. Qualitative Health Research. 1999;9(6):836-845. doi: 10.1177/104973299129122199

11. Glaser BG. Conceptualization: on theory and theorizing using grounded theory. International Journal of Qualitative Methods. 2002;1(2).

12. Field P, Morse J. Nursing research: the application of qualitative approaches. 1995.

13. Neuman WL Social research methods: qualitative and quantitative Approaches. 6th ed., Pearson Boston. 2006.

14. Chenitz, WC, Swanson JM. Qualitative research using grounded theory. In Chenitz W.C, Swanson, J.M (Eds), from practice to grounded theory. Menlo Park, Addison-Wesley. 1986.

15. Mills JE, Birks M. Grounded Theory. Qualitative Methodology: A practical guide. 2014.

16. Benoliel, JQ. Grounded theory and nursing knowledge. Qualitative Health Research. 1996;6(3):406-428. doi: 10.1177/104973239600600308

17. Stern PN. Eroding grounded theory. In Morse J (Ed.), Critical issues in qualitative research methods. Thousand Oaks, Sage. 1994.

18. Cutcliffe JR. Methodological issues in grounded theory. J Adv Nurs. 2000;31(6):1476-1484. doi: 10.1046/j.1365-2648.2000.01430.x

19. Goulding C. Grounded theory, ethnography and phenomenology: A comparative analysis of three qualitative strategies for marketing research. European Journal of Marketing. 2005;39(3/4):294-308. doi: 10.1108/03090560510581782

20. Backman K, Kyngas HA. Challenges of the grounded theory approach to a novice researcher. Nursing and Health Sciences. 1999;1(3):147153. doi: 10.1046/j.1442-2018.1999.00019.x

21. Heath H, Cowley S. Developing a grounded theory approach: a comparison of Glaser and Strauss. International Journal of Nursing Studies. 2004;41:141-150. doi: 10.1016/S0020-7489(03)00113-5

22. McCallin AM. Designing a grounded theory study: some practicalities. Nursing in Critical Care. 2003:8(5):203-208. doi: 10.1046/j.13621017.2003.00033.x

23. Strauss AL, Corbin JM. Basics of qualitative research: grounded theory procedures and techniques. Sage Publications. 1990. 
24. Wuest J. Grounded theory: the method. In P.L. Munhall (Ed.). Nursing research: a qualitative perspective 5th Edition: Sudbury: Jones and Bartlett Publishers. Inc. 2012: 225-256.

25. Crook D. The importance of symbolic interaction in grounded theory research on women's health. Health Care for Women International. 2001;22(1,2):11-27. doi:10.1080/073993301300003054

26. Morse J, Richards L. Readme first for a user's guide to Qualitative methods. London: SAGE Publications. 2002.

27. Schreiber R, Stern PN. In R.S. Schreiber \& P.N. Stern (Eds), Using grounded theory in nursing. New York: Springer. 2001:35-54.

28. Glaser BG. The Grounded Theory Perspective III: theoretical coding, Mill Valley, CA: Sociology Press. 2005.

29. Jones M. "Lights,...Action...Grounded Theory": Developing an understanding for the management of film production". Rhyzome. 2005;1(1):143-153. In Print

30. Burns N, Grove SK. Understanding nursing research: building an evidence-based practice (4th ed.). Philadelphia: Saunders Company. 2007.

31. Elliott N, Lanzenbatt, A. How to recognise a 'quality' grounded theory research study. Aust J Adv Nurs. 2005;22(3):48-52.
32. Mediani HS. Indonesian nurses management of pain in children: a grounded theory study. Doctoral thesis, Curtin University.2014.

33. Irurita V. Preserving integrity: a theory of nursing. In Greenwood, J (Ed), Nursing theory in Australia: development and application. Sydney: Harper Educational. 1996

34. Schreiber R, Stern PN, Wilson C. The context for managing depression and its stigma among black West Indian Canadian women. Journal of Advanced Nursing. 1998;17(3):510-517. doi:10.1046/j.13652648.1998.00549.x

35. Neill SJ. Containing acute childhood illness within family life: a substantive grounded theory. Journal of Child Health Care. 2010; 14(4):327-344. doi:10.1177/1367493510380078

36. Neill SJ, Cowley S, Williams C. The role of felt or enacted criticism in understanding parent's help seeking in acute childhood illness at home: A grounded theory study. Int J Nurs Stud.2013;50(6):757767. doi:10.1016/j.ijnurstu.2011.11.007.

37. Stern PN. Restructuring life after home loss by fire. Image: the journal of nursing scholarship. 1996;28(1):11-16. 